\title{
A case laboratory study on effect of quarry dust based geopolymer on physical and mechanical properties of laterit soil
}

\author{
Duc Van Bui ${ }^{1}$, Lam Phuc Dao², Manh Van Nguyen ${ }^{1}$, Anh Quoc Nong³ ${ }^{3}$ Kennedy 0.4 \\ ${ }^{1}$ Civil Engineering Faculty, Hanoi University of Mining and Geology, Vietnam \\ ${ }^{2}$ Civil Engineering Faculty, University of Transport Technology, Vietnam \\ ${ }^{3}$ Bac Kan City Department of Transportation and Communication, Vietnam \\ ${ }^{4}$ Department of Civil Engineering, Michael Okpara University of Agriculture, Umudike, P. M. B. 7267, \\ Umuahia 440109, Abia State, Nigeria
}

ARTICLE INFO

Article history:

Received $15^{\text {th }}$ Oct. 2020

Revised 23rd Nov. 2020

Accepted 31st Dec. 2020

Keywords:

CBR,

Geopolymer,

Quarry dust,

Shrinkage,

Swelling.

\section{ABSTRACT}

This paper presents a case study on the laboratory examination of quarry dust based geopolymer on some physical and mechanical properties of stabilized laterit soil. The laboratory test results indicate that both CBR and shrinkage limit of studied soil increased substantailly with increased rate of quarry dust based geopolymer (QD-based geopolymer). Specifically, the laterit soils were treated with QD-based geopolymer in the proportions of 10\%, 20\%, 20\%, 30\%, 40\%, 50\%, 60\%, respectively, by weight of dry soil; the CBR values were increased from $7.4 \%$ to $35.71 \%$ at proportion of $40 \%$ QD-based geopolymer. The obtained CBR value of $35.71 \%$ meets the requirement to be used as filled meterials for pavement purpose according to the TCVN 8857:2012. In constrast with the increase in CBR and shrinkage values, the swelling potential of treated soils was found to be decreased with raising QD-geopolymer proportion, for example, the swelling potential decreased from $14.5 \div 6.9 \%$ as adding 10, and $60 \%$ of $Q D$ - based geopolymer, respectively.

Copyright (C) 2020 Hanoi University of Mining and Geology. All rights reserved.

${ }^{*}$ Corresponding author

E - mail: buivanduc@humg.edu.vn

DOI: 10.46326/JMES.HTCS2020.07 


\title{
Tạp chí Khoa học Kỹ thuật Mỏ - Địa chất
}

Trang điện tử: http://tapchi.humg.edu.vn

\section{Nghiên cứu ảnh hưởng của hàm lượng geopolymer bột đá đến một số tính chất cơ lý của đất laterit}

\author{
Bùi Văn Đức ${ }^{1,}{ }^{*}$, Đào Phúc Lâm ${ }^{2}$, Nguyễn Văn Mạnh ${ }^{1}$, Nông Quốc Ánh ${ }^{3}$, Kennedy \\ O. 4 \\ ${ }^{1}$ Khoa Xây dưng, Đại học Mỏ-Địa chất Hà Nội, Bắc Tù Liêm, Hà Nội \\ ${ }^{2}$ Bộ môn Kết cấu - vật liệu, Khoa công trình, Đại học công nghệ giao thông vận tải, Thanh Xuân, Hà Nội \\ ${ }^{3}$ Sở giao thông vận tải Bắc Kạn, tỉnh Bắc Kạn \\ ${ }^{4}$ Khoa Xây dụng, Đại học Michael Okpara University of Agriculture, Bang Abia, Nigeria
}

\begin{tabular}{|c|c|}
\hline THÔNG TIN BÀI BÁO & TÓM TẮT \\
\hline $\begin{array}{l}\text { Quá trình: } \\
\text { Nhận bài 15/10/2020 } \\
\text { Sưa xong 23/11/2020 } \\
\text { Chấp nhận đăng 31/12/2020 } \\
\text { Tù khóa: } \\
\text { Bột đá, } \\
\text { CBR, } \\
\text { Co ngót, } \\
\text { Geopolymer, } \\
\text { Gia cố đất, } \\
\text { Trương nở. }\end{array}$ & 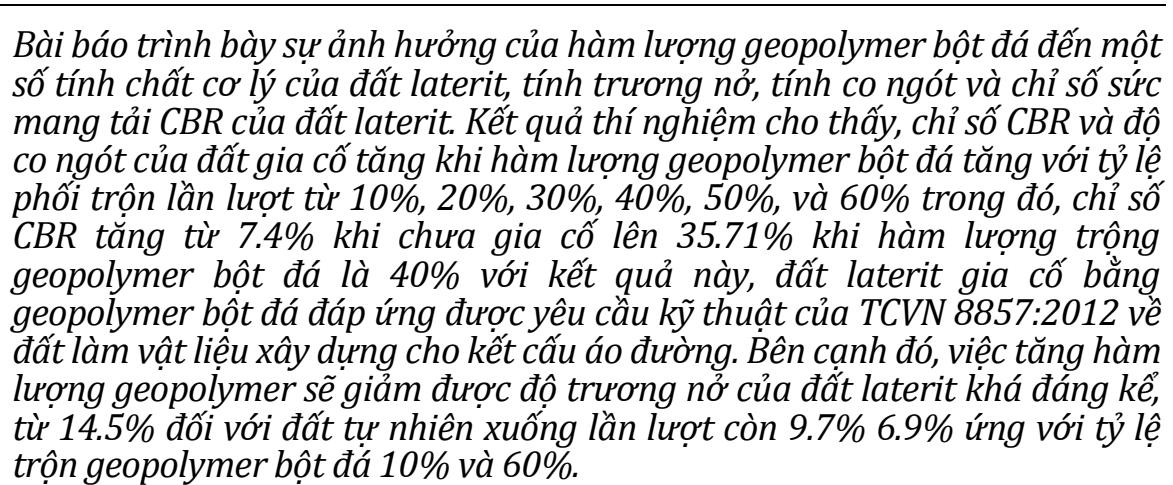 \\
\hline
\end{tabular}

(C) 2020 Trường Đại học Mỏ - Địa chất. Tất cả các quyền được bảo đảm.

\section{Mở đầu}

Thực tế cho thấy, nguồn vật liệu đảm bảo chỉ tiêu cơ lý theo các yêu cầu, các tiêu chuẩn kỹ thuật ngày càng khan hiếm, trong số đó có thể kể đến như nguồn vật liệu cho nền đường đắp. Tại các quốc gia có khí hậu nhiệt đới gió mùa, lớp đất mặt có thể khai thác chủ yếu là đất tàn tích với loại đất chủ yếu là đất laterit có đặc điểm điển hình như: hàm lượng hạt mịn lớn, tính sét cao; dễ thay đổi

\footnotetext{
*Tác giả liên hệ

E - mail: buivanduc@humg.edu.vn

DOI: 10.46326/JMES.HTCS2020.07
}

thể tích khi chịu sự tác động của độ ẩm; khả năng mang tải thấp, các chỉ tiêu cơ lý thường không đảm bảo quy định. Do đó, với mục tiêu giảm áp lực xử lý chất thải công, nông nghiệp và đồng thời hướng tới việc tận dụng nguồn vật liệu tại chỗ phục vụ xây dựng công trình hạ tầng thì xu hướng tận dụng các phụ phẩm công-nông nghiệp để cải thiện tính chất cơ lý của vật liệu đất tại chỗ, đất laterit, đã và đang nhận được nhiều sự quan tâm, trong đó hoạt động nghiên cứu và ứng dụng kỹ thuật gia cố đất phần lớn được thực hiện dựa trên nguyên lý của công nghệ geopolymer do giáo sư người Pháp Davidovits đề xuất năm 1978 (Abdel-Gawwad \& Abo-El-Enein, 2016; Davidovits, 2013). Bản chất 
chung của công nghệ này là thay thế chất dính kết xi măng truyền thống bằng chất chất dính kết geopolymer bằng cách tạo ra phản ứng trùng ngưng giữa các tiền chất giầu silicat và alumin trong môi trường kiềm. Theo Joseph Davidovits, 2013 công nghệ geopolymer không phụ thuộc vào $\mathrm{CaCO}_{3}$ nên có thể giảm lượng phát thải khí $\mathrm{CO}_{2}$ từ $(40 \div 90) \%$ so với công nghệ xi măng truyền thống.

Một số nghiên cứu gần đây sử dụng hỗn hợp bột vôi sống, tro bay và $10 \%$ xi măng Portland thông thường để gia cố đất sét cho thấy đặc tính đầm nén của đất gia cố được cải thiện khá đáng kể, cụ thể như dung trọng tăng từ $16,4 \mathrm{kN} / \mathrm{m}^{3}$ lên 17,8 $\mathrm{kN} / \mathrm{m}^{3}$; chỉ số sức mang tải CBR của đất sét tăng từ $7.6 \div 17.8 \%$; và cường độ chịu nén của mẫu đất sét gia cố tăng từ $78,6 \div 223 \mathrm{kPa}$ (Kennedy và nnk., 2018; Kumar và nnk., 2007). Kết quả nghiên cứu sử dụng hỗn hợp tro bay $10 \%$ và bột vôi sống $5 \%$ gia cố đất có tính sét cao của (Zhou, 2019) cho thấy, chỉ số dẻo của đất có thể giảm xuống 64,9\%, độ trương nở thể tích giảm xuống khoảng 10\%.

Tác giả (Soosan, 2001) cho rằng bột đá có cường độ kháng cắt cao, góc ma sát trong khoảng 40 độ, có thể thay thế cát tự nhiên khi gia cố đất. Kết quả thí nghiệm của (Soosan, 2001) với ba loại đất khác nhau: đất đỏ (đất laterit), đất sét ven biển, đất sét giàu kaolinit cho thấy giới hạn chảy của mẫu đất gia cố giảm khi hàm lượng bột đá trộn tăng.

Kết quả nghiên cứu tổng quan của (Abdullah, 2020) cho thấy việc gia cố đất bằng công nghệ geopolymer cải thiện đáng kể chỉ tiêu cơ lý, tính chất cơ học và độ bền của khá nhiều các loại đất khác nhau, như: đất sét, đất sét pha, cát hạt mịn, đất hoàn thổ (loess soil), cát pha,... bên cạnh việc sử dụng tro bay, thì một số chất thải rắn công nghiệp khác cũng đã được nghiên cứu sử dụng như: tro xỉ, vôi bột.

Từ một số kết quả phân tích trên có thể nhận thấy, công nghệ geopolymer đã và đang được nghiên cứu và áp dụng khá rộng rãi trong việc cải thiện tính chất của một số loại đất khác nhau; tuy nhiên, các nghiên cứu mới dừng ở việc trộn một hoặc hai thành phần chất thải rắn, việc sử dụng hỗn hợp phức hợp với nhiều thành phần chất thải rắn công nghiệp để gia cố đất Laterit còn tương đối hạn chế. Do đó, bài báo trình bày một số kết quả thí nghiệm trong phòng đánh giá sự ảnh hưởng của hàm lượng bột đá với chất dính kết
Geopolymer đến một số tính chất cơ lý của đất Laterit.

\section{Cơ chế phản ứng và hình thành liên kết của geopolymer}

(Provis, 2009) sơ đồ hóa quá trình geopolymer hóa theo sơ đồ dưới đây (Hình 1). Theo đó, quá trình geopolymer hóa được bắt đầu bằng quá trình hòa tan của vật liệu giàu Si-Al bởi dung dịch kiềm. Kết quả của quá trình hòa tan là các đơn phân tử Gel 1 còn nhiều nguyên tử $\mathrm{Al}$ trong cấu trúc. Trong môi trường kiềm các đơn phân tử Gel 1 phản ứng trùng ngưng với nhau tạo thành Gel2 có số lượng nguyên tử $\mathrm{Al}$ giảm đi và nguyên tử Si tăng lên. Các Gel2 về bản chất là oligomer tổng hợp từ Gel1 được polymer hóa tạo các chuỗi polymer mạch dài. Các chuỗi polymer này tiếp tục phát triển để tạo thành bộ khung $3 \mathrm{D}$ của geopolymer.

Nói một cách khác, quá trình geopolymer hóa là quá trình bao gồm các phản ứng hóa học liên quan đến sự tương tác giữa vật liệu giàu khoáng Si-Al với môi trường kiềm với tốc độ nhanh. Sản phẩm được tạo ra từ quá trình này là các chuỗi mạch thẳng và vòng có cấu trúc không gian $3 \mathrm{D}$ được tạo thành từ các liên kết -Si-O-Al-O. Theo đó, một cách tổng quát, các chất giàu khoáng $\mathrm{Si}-\mathrm{Al}$ sẽ bi kiềm hóa bởi dung dịch kiềm thổ- phương trình (1.2) hoặc bởi dung dịch kiềm Silicat - phương trình (1.3) tạo ra các tiền chất Geopolymer (Hình $1,2)$. Các tiền chất này tiếp tục phản ứng trùng ngưng với nhau trong môi trường kiềm thổ hoặc kiềm Silicat tạo ra bộ khung xương Geopolymer.

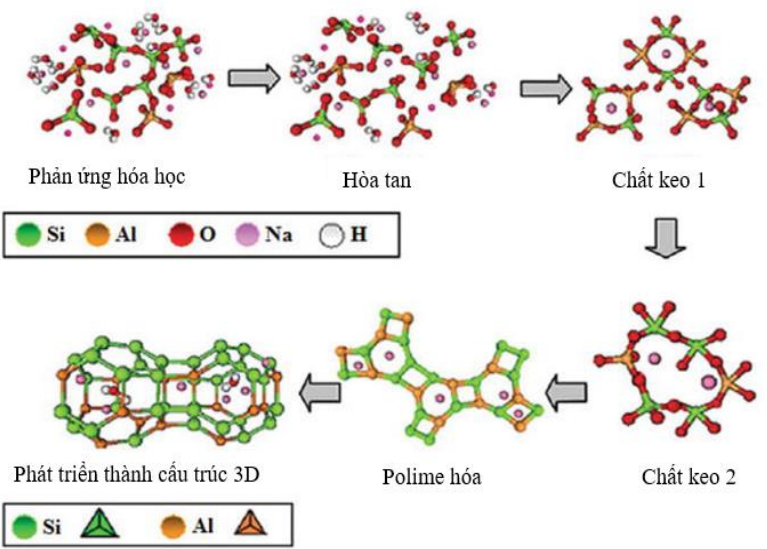

Hình 1. Cơ chế hình thành liên kết Geopolymer (Provis \& Van Deventer, 2009). 


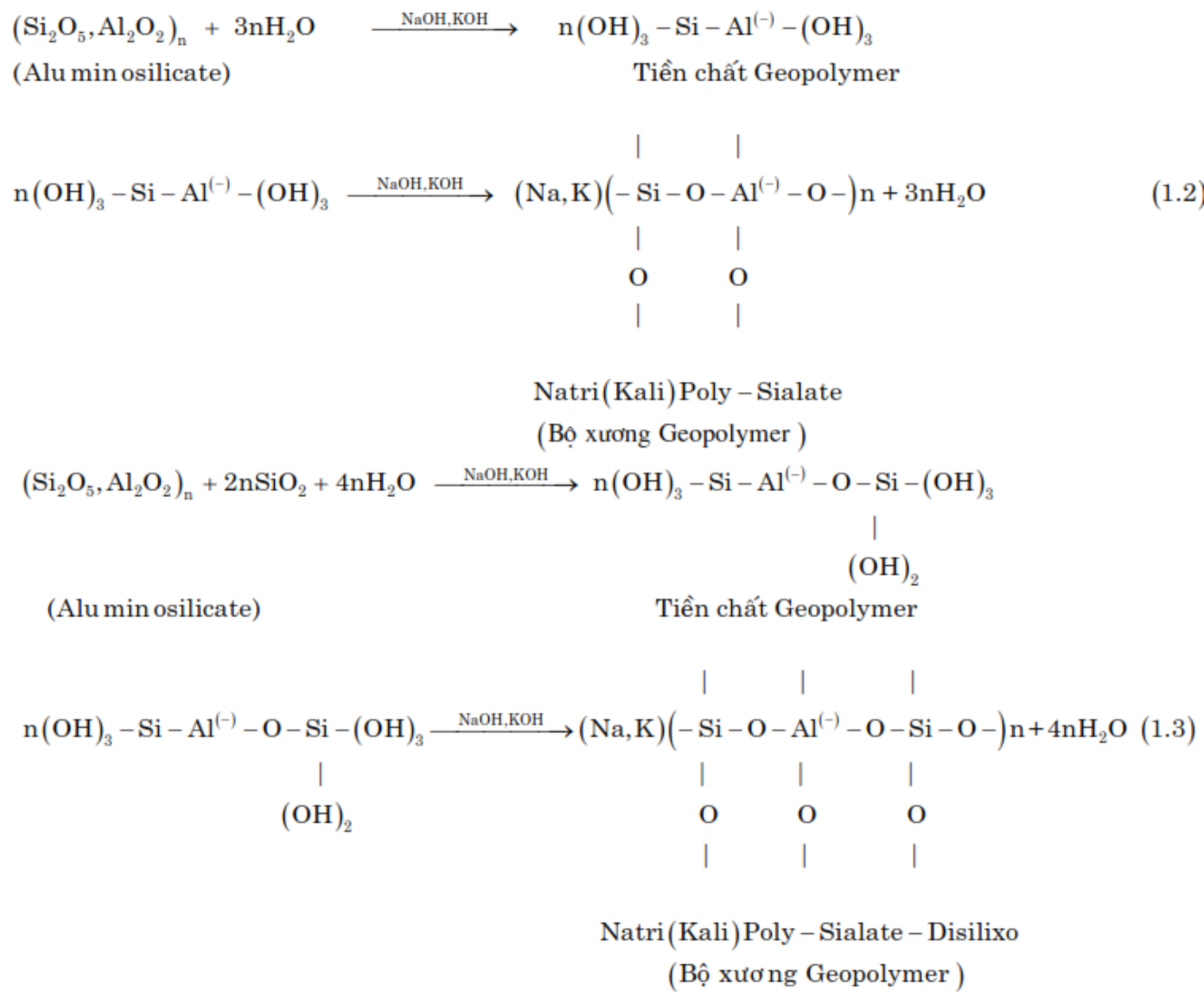

Hình 2. Phương trình phản úng hóa học geopolymer hóa (Provis \& Van Deventer, 2009).

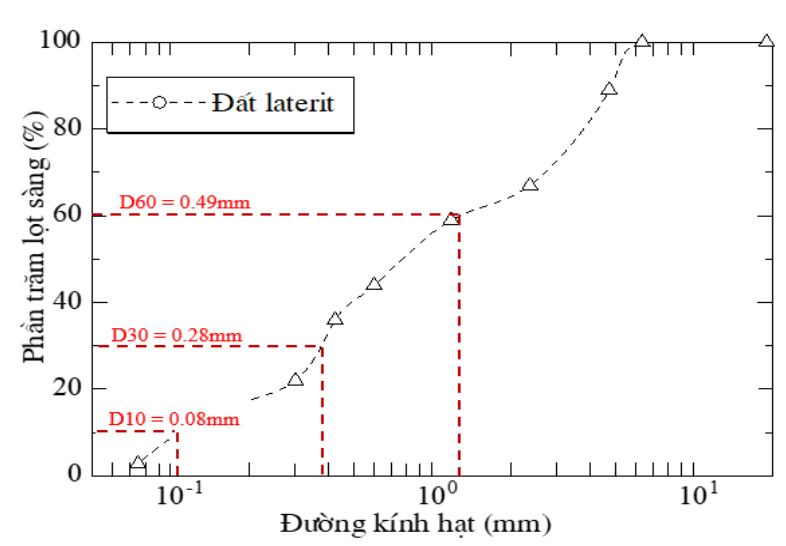

Hình 3. Biểu đồ thành phần cỡ hạt của mẫu đất.

\section{Vật liệu và thí nghiệm}

\subsection{Vật liệu}

\subsection{1. Đất laterit}

Đất laterit được sử dụng được lấy tại tỉnh Đak Nông - Tây Nguyên, với hệ số cấp phối Cc và hệ số đồng đều $\mathrm{Cu}$ lần lượt là 2.0 và 6.13 , tỷ trọng hạt $G s$ $=2.08$, độ ẩm tự nhiên và tối ưu có giá trị: $24.5 \%$,
$31.5 \%$. Giới hạn Atterberg của mẫu đất $L L=46 \%$, $P L=26 \%, P I=23$ và $S L=8$. Theo phân loại AASHTO M145 thì mẫu đất thuộc nhóm A-2-7.

Hàm lượng hạt lọt sàng tại mắt sàng 0.425 mm cao, gần 45\%, do đó mẫu đất thuộc loại đất hạt rời có hàm lượng hạt bụi, mịn và tính sét (tính dẻo) cao, thay đổi thể tích lớn khi chịu sự tác động của độ ẩm. Biểu đồ thành phần cỡ hạt của mẫu đất thể hiện tại Hình 3.

\subsubsection{Chất thải rắn công nghiệp}

Chất thải rắn sử dụng trong bài báo là phụ phẩm của một số quá trình sản xuất công nghiệp nặng, bao gồm: tro bay, xỉ thép, và bột đá (bụi đá). Trong đó, bột đá được thu thập tại khu sản xuất cát nghiền từ đá vôi nằm trên địa bàn thị trấn Xuân Mai, huyện Chương Mỹ Hà Nội; tro bay và tro xỉ được lấy tại nhà máy nhiệt điện Thái Nguyên. Các mẫu vật liệu thí nghiệm sau khi thu thập sẽ hong khô, chế bị trong phòng thí nghiệm trước khi sử dụng (Hình 4).

Tỷ lệ phối trộn hỗn hợp chất kết dính geopolymer sử dụng chất thải rắn công nghiệp 
được thể hiện tại Bảng 1, 2 thể hiện thành phần hóa học chính của các loại vật liệu sử dụng trong thí nghiệm.

$$
D_{\text {Tr.n }}=\frac{\Delta h}{h_{o}} x 100
$$

\subsection{Thí nghiệm}

\subsubsection{Thí nghiệm trương nở}

Thí nghiệm độ trương nở của đất được thực hiện theo TCVN 8719:2012 với thiết bị thí nghiệm trương nở được thể hiện tại Hình 5 . Theo đó, độ trương nở của đất bất kỳ được đánh giá thông qua sự tăng chiều cao của mẫu đất một cách tự do, không chịu tác dụng bất kỳ của một tải trọng một trục được đặt phản áp trên bề mặt mẫu đất.

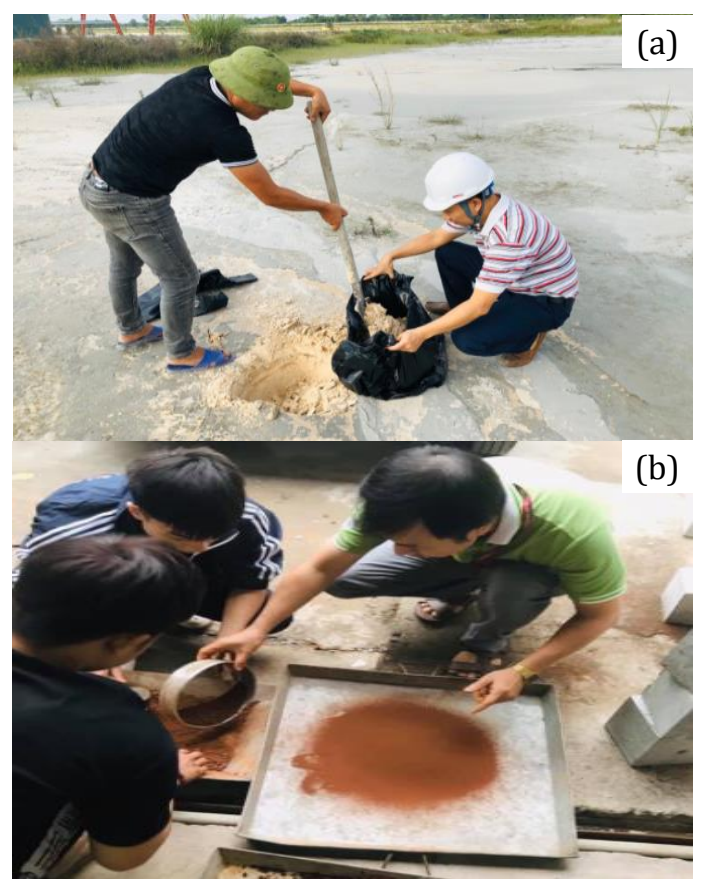

Hình 4. Thu thập mẫu bột đá (bụi đá) và thí nghiệm xác định chỉ tiêu cơ lý mẫu đất.

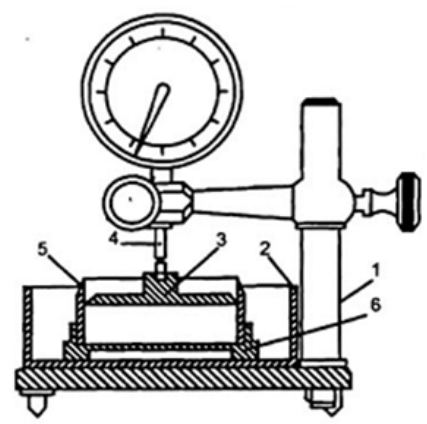

CHÚ DẪN:

1. Bàn và giá đỡ

2. Hộc chứa nước

3. Pitstong

4. Đồng hồ đo biến dạng

5. Dao vòng chứa mẫu

6. Hộc đặt dao vòng chứa mẫu

Hình 5. Thiết bị thí nghiệm tính trương nở (TCVN 8719:2012).
Mẫu đất sau khi được đầm chăht ở độ ẩm tối ưu sẽ được ngâm trong nước; và tiến hành quan trắc lượng trương nở của mẫu đất theo thời gian cho đến khi đất dừng trương nở. Theo đó, độ trương nở của đất được xác định theo công thức:

Trong đó: $\Delta h$ - lượng biến dạng nở của mẫu đất sau khi chấm dứt trương nở, mm; $h_{o}$ - chiều cao ban đầu của mẫu thí nghiệm, mm.

\subsubsection{Thí nghiệm co ngót của đất}

Thí nghiệm độ co ngót của đất được thực hiện theo TCVN 8720:2012. Theo đó, độ co ngót của đất là mức độ bi giảm thể tích của đất do ngót khô khi đạt tới giới hạn co ngót; về trị số, đó là tỷ số giữa lượng thể tích đất bị giảm do ngót khô và thể tích ban đầu của đất, ký hiệu là Dc.ng, tính bằng $\%$ theo thể tích. Mẫu đất thí nghiệm đã được xác định thể tích và các kích thước ban đầu để hong khô trong không khí ở trong phòng và quan trắc sự thay đổi thể tích của mẫu đất trong quá trình đất bị ngót khô cho đến khi thể tích đất không thay đổi; cứ sau thời gian $4 \mathrm{~h}$ thực hiện đo số liệu, số đo chiều cao và đường kính của mẫu thí nghiệm đều giảm không quá $0,1 \mathrm{~mm}$, thì được cho là đất chấm dứt co ngót và kết thúc quan trắc; sau đó, xác định thể tích mẫu đất bằng phương pháp thí nghiệm bọc sáp theo quy định của TCVN 4202 : 2012 . Từ các số liệu thí nghiệm, tính toán được các đặc trưng co ngót của đất. Độ co ngót thể tích của đất, được biểu thị bằng \% theo thể tích và tính theo công thức sau:

$$
D_{c . n g}=\left(\frac{V_{o}-V_{k}}{V_{o}}\right) \times 100
$$

Trong đó: $V_{o}, V_{k}$ - thể tích ban đầu và sau khi kết thúc co ngót của mẫu đất thí nghiệm, $\mathrm{cm}^{3}$.

\subsubsection{Thí nghiệm CBR}

Thí nghiệm CBR được thực hiện trong phòng theo tiêu chuẩn TCVN 8821:2011, theo đó, chỉ số CBR được xác định như sau:

$$
C B R=\frac{P}{69} \times 100
$$

Trong đó: $C B R$ - giá trị CBR tính với chiều sâu ép lún 2,54 mm $(0,1 \mathrm{in}), \%$; $P$ - là áp lực nén trên mẫu thí nghiệm ứng với chiều sâu ép lún $2,54 \mathrm{~mm}$ $(0,1 \mathrm{in}), \mathrm{daN} / \mathrm{cm}^{2}$.

\subsubsection{Quy trình chế bị mẫu chung}


Quá trình chế bị mẫu đất và tổng hợp chất kết dính geopolymer được thể hiện tại Hình 6; cụ thể hỗn hợp geopolymer được tổng hợp từ tro bay (loại $C$ - theo ASTM), xỉ thép và dung dịch kiềm với tỷ lệ lần lượt là $22 \%, 44 \%$, và $4.8 \%$ theo khối lượng thể tích đất khô. Hỗn hợp Geopolymer tiếp tục được trộn đều với đất, xi măng portland để tạo thành hỗn hợp đất+GPC. Sau cùng, hỗn hợp (đất+GPC) được trộn với các tỷ lệ bột đá khác nhau từ 10, 20, 30, 40, 50, 60\% trước khi tiến hành các thí nghiệm liên quan. Trong tất cả các thí nghiệm đánh giá sự ảnh hưởng của hàm lượng bột đá tới tính chất cơ lý của mẫu đất gia cố thì mẫu đất gia cố sẽ được trộn với hàm lượng nước tối ưu.

\section{Kết quả thí nghiệm và thảo luận}

\section{1. Ảnh hưởng của hàm lượng bột đá đến tính trương nở của đất}

Độ trương nở, $\mathrm{S}_{\mathrm{w}}$ được xác định theo công thức:

$$
S_{w}=\frac{S_{1}-S_{2}}{H} \times 100
$$

Kết quả thí nghiệm cho thấy, độ trương nở của đất tăng theo thời gian mẫu ngâm ở trong nước đối với đất tự nhiên và các loại đất được gia

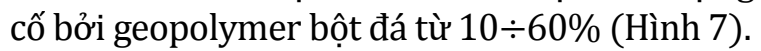

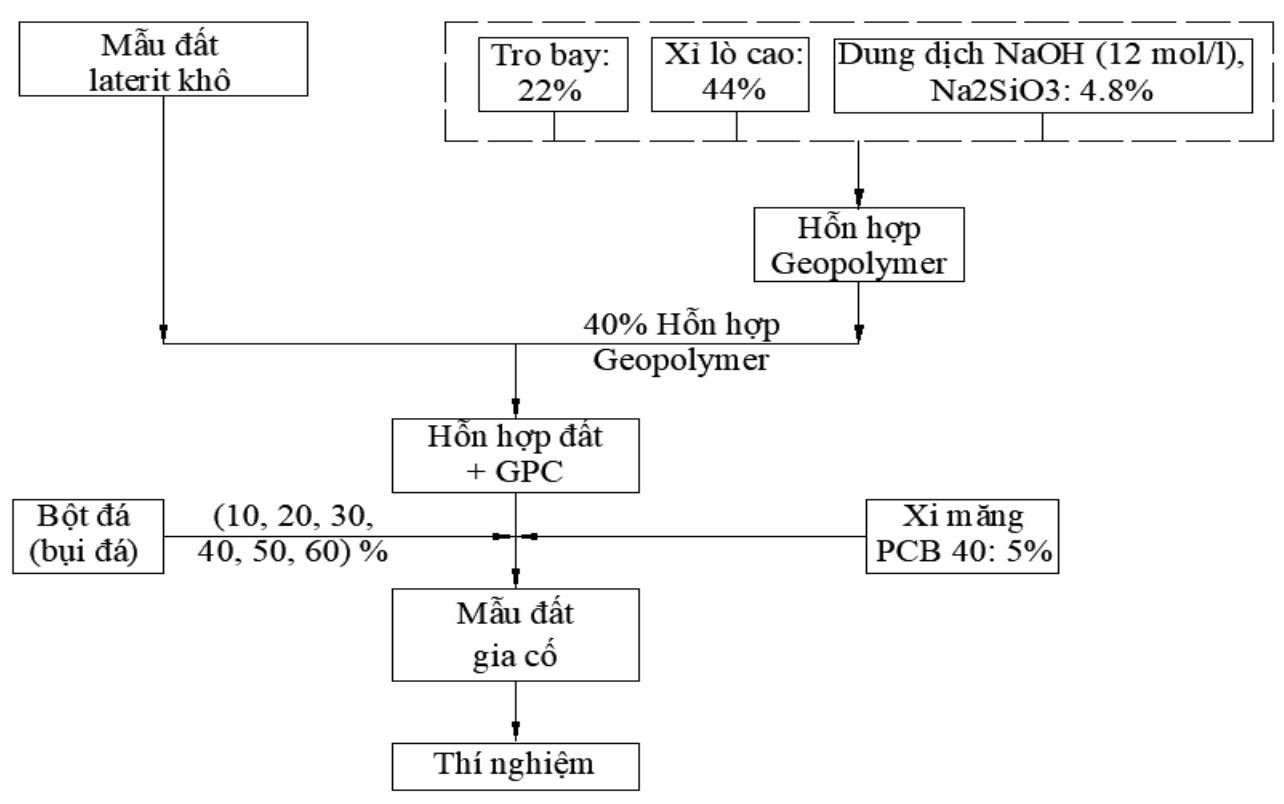

Hình 6. Quy trình chế tạo mẫu thí nghiệm.

Bảng 1. Tỉ lệ thành phần vật liệu chất kết dính Geopolymer.

\begin{tabular}{|c|c|c|c|c|c|}
\hline TT & Tro bay & Tro xî & Xi măng PCB 40 & Chất kiềm hoạt hóa (dung dịch $\mathrm{NaSiO}_{3} / \mathrm{NaOH}$ ) & Bột đá (bụi đá) \\
\hline 1 & \multicolumn{5}{|c|}{ Tỷ lệ (\%) theo khối lượng đất khô } \\
\hline 2 & $22 \%$ & $44 \%$ & $5 \%$ & $12 \mathrm{Mol} / \mathrm{l}$ & Thay đổi \\
\hline
\end{tabular}

Bảng 2. Thành phần hóa học chính của vật liệu.

\begin{tabular}{|c|c|c|c|c|c|c|c|c|c|c|c|c|c|}
\hline \multirow{2}{*}{ Vật liệu } & \multicolumn{13}{|c|}{ Thành phần hóa học chính (\% khối lượng) } \\
\hline & $\mathrm{SiO}_{2}$ & $\mathrm{Al}_{2} \mathrm{O}_{3}$ & $\mathrm{CaO}$ & $\mathrm{Fe}_{2} \mathrm{O}_{3}$ & $\mathrm{MgO}$ & $\mathrm{K}_{2} \mathrm{O}$ & $\mathrm{Na}_{2} \mathrm{O}$ & $\mathrm{TiO}_{2}$ & LOI & $\mathrm{P}_{2} \mathrm{O}_{5}$ & $\mathrm{SO}_{3}$ & $\mathrm{MnO}$ & CaO tự do \\
\hline Đất laterit & 42.83 & 25.83 & 0.14 & 21.36 & 0.62 & 0.19 & 0.02 & 0.8 & - & 0.08 & - & 0.02 & - \\
\hline Xi măng & 21.45 & 4.45 & 63.81 & 3.07 & 2.42 & 0.83 & 0.20 & 0.22 & - & 0.11 & 2.46 & & 0.64 \\
\hline Bột đá & 63.48 & 17.72 & 5.56 & 1.7 & 4.65 & 3.69 & 2.51 & 0.18 & - & - & 2.11 & - & - \\
\hline Tro bay & 63.45 & 4.14 & 12.11 & 1.23 & 0.78 & 1.09 & - & - & - & - & - & - & - \\
\hline Tro xỉ & 21.45 & 4.45 & 63.81 & 3.07 & 2.42 & 0.83 & & & & & & & \\
\hline
\end{tabular}


Điều này được giải thích là do đất càng ở lâu trong nước thì lượng nước hấp thụ của kết cấu đất (soil matrix) sẽ ngày càng tăng cho đến khi đất đạt đến độ ẩm bão hòa lớn nhất $Z$ (Saturation limit).

Theo (Casagrande, 1932), $Z$ được xác định bằng công thức như sau:

$$
Z=\sqrt{15.2(L L \%-16,3)}+9 \%
$$

Trong đó, $L L$ giá trị giới hạn chảy của mẫu đất, $L L=46 \%$, do vậy độ ẩm bảo hòa lớn nhất, $\mathrm{Z}$ $=30.3 \%$.

Kết quả thí nghiệm cũng cho thấy, độ trương nở của đất gia cố giảm khi hàm lượng geopolymer bột đá tăng, điều này được giải thích là do quá trình trao đổi cation tự nhiên, các phản ứng geopolymer hóa giữa môi trường kiềm với các hạt sét của đất đã keo tụ, kết dính các các hạt kích thước nhỏ trở thành các hạt có kích thước lớn hơn, từ đó làm thay đổi cấu trúc đất từ đất sét bụi (clayed silts) sang đất dạng hạt rời (granular soil) với khả năng hấp thụ nước kém hơn dẫn đến độ trương nở của đất giảm đi. Độ trương nở này sẽ càng giảm nếu phản ứng geopolymer hóa nhiều hơn. Vì vậy, độ trương nở của đất giảm đi khi tăng tỉ lệ geopolymer bột đá trong hỗn hợp đấtgeopolymer bột đá. Bên cạnh đó, đường cong trương nở của các loại đất đều phản ánh rất rõ 03 giai đoạn. Đối với đất gia cố bằng geopolymer bột đá đều cho thấy 03 giai đoạn trương nở: giai đoạn 1 (khởi đầu) từ $0 \div 7$ giờ sau khi ngâm mẫu, giai đoạn trương nở thứ cấp xảy ra từ $7 \div 56$ giờ, và giai đoạn cuối xảy ra sau 56 giờ kể từ thời điểm ngâm mẫu, ở giai đoạn này sự trương nở của đất xảy ra không đáng kể (tắt trương nở). Tuy nhiên, đối với đất tự nhiên mới quan sát được 2 giai đoạn: giai đoạn khởi đầu bắt đầu từ giờ thứ 3 và giai đoạn sơ cấp với sự trương nở của đất vẫn tiếp tục phát triển, chưa có dấu hiệu dừng lại. Điều này chủ yếu do cấu trúc của đất (texture) là loại sét bụi, độ chặt nhỏ, tỉ diện bề mặt lớn hút nước mạnh dẫn đến trương nở mạnh. Giai đoạn thứ cấp chưa được quan sát thấy, chứng tỏ sự hiệu quả của việc sử dụng geopolymer - bột đá trong việc ổn định tính trương nở của đất, tuy rằng sự ổn định này diễn ở khoảng thời gian tương đối dài (sau ngày thứ 56). Đất tự nhiên laterit nghiên cứu, ở 77 giờ tuổi thí nghiệm, độ trương nở đo được khoảng 14,5\% > $12 \%$ và chưa có dấu hiệu kết thúc. Như vậy, có thể xếp đất laterit nghiên cứu vào loại đất có độ trương nở cao (TCVN 8719:2012). Các loại đất được cải thiện bởi geopolymer - bột đá ở tuổi 77 giờ, đều đã tắt trương nở và có giá trị giảm từ $9.7 \div 6.9 \%$ được xếp vào loại đất có độ trương nở trung bình.

\section{2. Ảnh hưởng của hàm lượng bột đá đến tính co ngót của đất}

Thí nghiệm độ co ngót của đất được thực hiện theo TCVN 8720:2012. Kết quả thí nghiệm cho thấy, độ co ngót tăng cùng với tỉ lệ geopolymer bột đá. Điều này được giải thích là các quá trình trao đổi cation, các phản ứng geopolymer hóa giữa môi trường kiềm với các hạt sét của đất đã keo tụ và kết dính các hạt đất nhỏ trở thành các hạt đất lớn hơn, thay đổi bản chất khoáng vật của các hạt sét theo hướng giảm khả năng hấp thụ nước. Nhờ vậy, cấu trúc của đất từ đất hạt mịn ưa nước sang dạng đất hạt rời kém hấp thụ nước hơn. Từ sự chuyển pha cấu trúc đó, khiến đất được gia cố bởi geopolymer bột đá với các tỉ lệ khác nhau có độ ẩm thấp. Tỉ lệ geopolymer bột đá càng nhiều thì độ ẩm của khối đất gia cố đó càng nhỏ, độ ẩm càng nhỏ thì lực hút mao dẫn của đất càng lớn, các hạt đất do vậy càng được kéo sát vào nhau, dẫn đến thể tích của đất được giảm mạnh.

Đất laterit tự nhiên sau $24 \mathrm{~h}$ vẫn chưa cho thấy giới hạn co ngót được thiết lập (Hình 8), trong khi đó với các đất được xử lý bằng geopolymer bột đá đều cho thấy thời gian kết thúc co ngót là 20 h sau khi tiến hành thí nghiệm.

\section{3. Ảnh hưởng của hàm lượng bột đá đến chỉ số CBR của đất gia cố}

Hình 9 trình bày kết quả đặc xác định chỉ số được xử lý bằng chất dính kết geopolymer bột đá

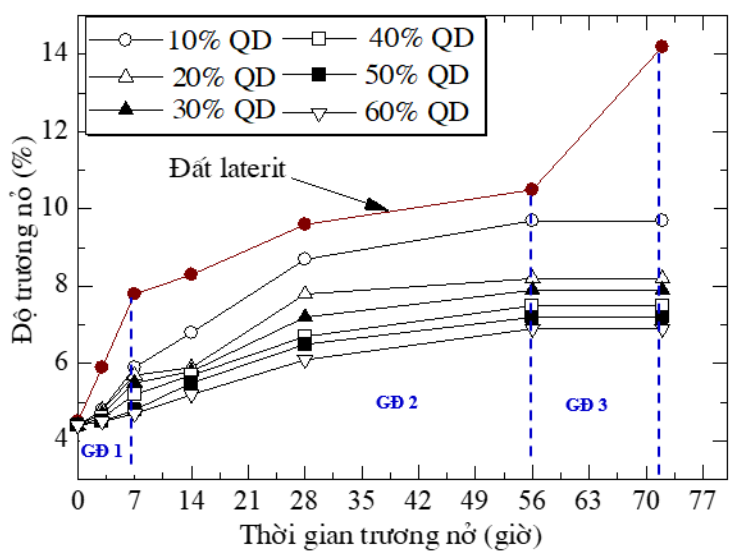

Hình 7. Độ trương nở của mẫu đất laterit gia cố. 


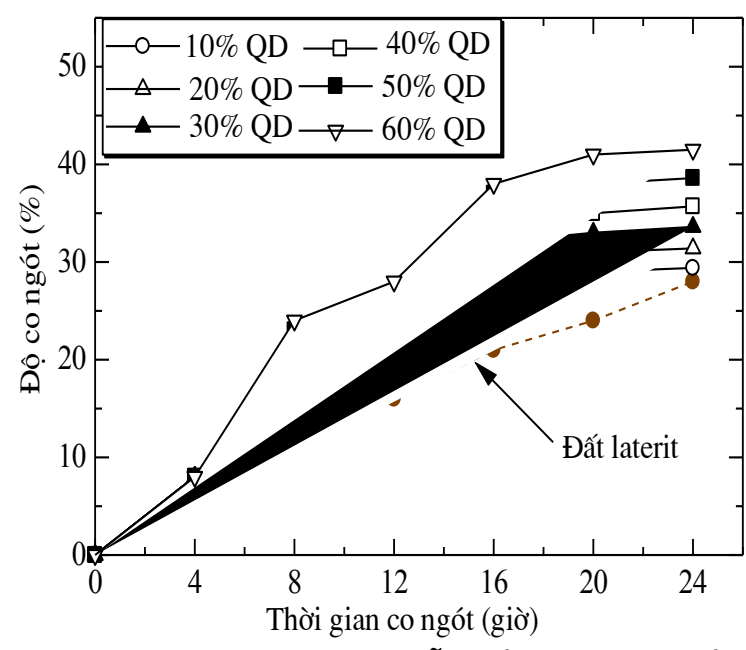

Hình 8. Độ co ngót của mẫu đất laterit gia cố.

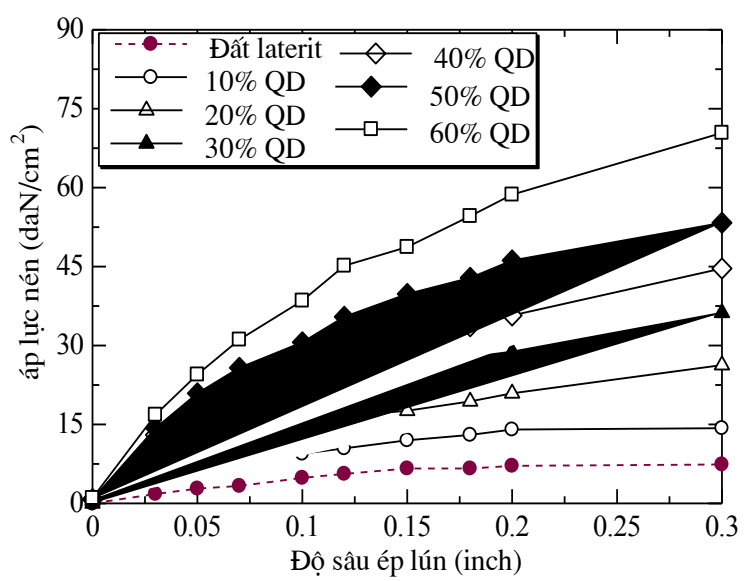

Hình 9. Chỉ số CBR của mẫu đất gia cố.

với các tỉ lệ khác nhau, kết quả thu được cho thấy chỉ số CBR tăng khi tăng hàm lượng geopolymer bột đá tăng, điều này cho thấy hiệu quả của việc gia cố đất laterit bằng chất kết dính geopolymer bột đá.

Chỉ số CBR của đất laterit tự nhiên khá nhỏ, chỉ đạt khoảng $7.4 \%$ và không đạt yêu cầu làm vật liệu kết cấu áo đường theo TCVN 8857:2012, chỉ phù hợp làm đất xây dựng nền đường cấp III, cấp IV có sử dụng lớp mặt $\mathrm{A}$ theo quy định của TCVN9436:2012. Tuy nhiên, khi tăng tỉ lệ geopolymer bột đá lên 40\%, thì giá trị CBR đạt $35.71 \%>[\mathrm{CBR}]=30$, với kết quả này, đất laterit gia cố đáp ứng được yêu cầu kỹ thuật của TCVN 8857:2012 về đất làm vật liệu xây dựng cho kết cấu áo đường, cụ thể làm lớp móng trên, dưới cho các kết cấu áo đường sử dụng lớp mặt A1, A2.

\section{Kết luận}

Kết quả nghiên cứu bước đầu cho thấy geopolymer bột đá có khả năng cải thiện khá tốt đất laterit về các đặc tính địa kỹ thuật, cụ thể:

- Chỉ số CBR tăng khi tăng hàm lượng geopolymer bột đá tăng;

- Đất laterit tự nhiên có độ trương nở cao, lên đến $14.5 \%$ ở thời gian bảo dưỡng 77 giờ tuổi. Tuy nhiên, khi được gia cố bởi geopolymer -bột đá, việc trương nở đã được ổn định và tắt ở thời gian bảo dưỡng 56 giờ. Điều này cho thấy tính khả thi của việc sử dụng geopolymer - bột đá trong việc ổn định thể tích cho các loại đất có tính trương nở cao.

\section{Lò̀i cảm ơn}

Bài báo được tài trợ bởi Bộ Giáo dục và Đào tạo thông qua đề tài mã số B2019 - MDA - 08.

\section{Đóng góp của các tác giả}

Các nội dung trong bài báo được thực hiện và hoàn thành bởi sự phối hợp của tất cả các tác giả trong bài báo.

\section{Tài liệu tham khảo}

Abdel-Gawwad, H. A., (2016). A novel method to produce dry geopolymer cement powder. HBRC Journal, 12(1), 13-24.

Abdullah, H. H., (2020). Review of Fly-Ash-Based Geopolymers for Soil Stabilisation with Special Reference to Clay. Geosciences, 10(7), 249.

Casagrande, A. (1932). Research on the Atterberg limits of soils. Public Roads, 13(8), 121-136.

Davidovits, J., (2013). Geopolymer cement. A Review. Geopolymer Institute, Technical Papers, 21, 1-11.

Kennedy, C., (2018). Comparative Evaluation of Cementitious Agents Composite materials on Strength Improvement Behavior of Black Cotton Clay Soil. European Journal of Advances in Engineering and Technology, 5(6), 368-374.

Kumar, A., (2007). Influence of fly ash, lime, and polyester fibers on compaction and strength properties of expansive soil. Journal of Materials in Civil Engineering, 19(3), 242-248. 
Provis, J. L., (2009). Geopolymers: Structures, processing, properties and industrial applications. Elsevier.

Soosan, T. G., (2001). Use of quarry dust in embankment and highway construction.
Proceedings of Indian Geo-Technical Conference, 274-277.

Zhou, S., (2019). Study on physical-mechanical properties and microstructure of expansive soil stabilized with fly ash and lime. Advances in Civil Engineering, 2019. 